\title{
Kinetics of lung tissue factor expression and procoagulant activity in bleomycin induced acute lung injury
}

Li Ma' ${ }^{1}$ Ciara M. Shaver ${ }^{2}$, Brandon S. Grove ${ }^{2}$, Daphne B. Mitchell ${ }^{2}$, Nancy E. Wickersham², Robert H. Carnahan ${ }^{3}$, Tracy L. Cooper ${ }^{4}$, Brittany E. Brake ${ }^{4}$, Lorraine B. Ware ${ }^{2,5}$ and Julie A. Bastarache ${ }^{2^{*}}$

\begin{abstract}
Background: Activation of coagulation by expression of tissue factor (TF) in the airspace is a hallmark of acute lung injury (ALI) but the timing of TF activation in relationship to increases in lung permeability and inflammation are unknown.

Methods: To test the hypothesis that TF is upregulated early in the course of acute bleomycin lung injury and precedes increased permeability and inflammation we studied the early course of bleomycin-induced ALI in mice. Mice were treated with $0.04 \mathrm{U}$ intratracheal bleomycin or vehicle control and bronchoalveolar lavage (BAL) and lung tissue were collected daily for 7 days. Whole lung TF mRNA was determined by QT-PCR. TF protein was assessed by ELISA and immunostaining. BAL procoagulant activity was measured by BAL clot time and thrombin-antithrombin complexes. Inflammation was assessed by BAL cell count, differentials and CXCL1/KC concentration. Lung permeability was assessed by BAL protein and lung wet to dry weight ratio.

Results: Expression of CXCL1 occurred by day 1. BAL protein and lung wet-to-dry weight ratio increased significantly by day 3. TF mRNA and BAL procoagulant activity peaked on day 4 while whole lung TF protein peaked on day 6 . Changes in permeability and procoagulant activity preceded inflammatory cell influx which was maximal at day 6 while whole lung TF protein peaked along with inflammation.
\end{abstract}

Conclusion: These data demonstrate that cytokine upregulation is the earliest response to bleomycin administration, followed by increased lung permeability, upregulation of TF, and recruitment of inflammatory cells.

Keywords: Acute lung injury; Acute respiratory distress syndrome; KC; Inflammation; Coagulation; Permeability; Pulmonary edema

\section{Background}

Acute lung injury (ALI) and Acute Respiratory Distress Syndrome are caused by local or systemic insults and involves loss of alveolar-capillary barrier integrity with influx of protein-rich edema fluid into the airspace, migration of inflammatory cells such as neutrophils and macrophages into the affected lung $[1,2]$ and activation of procoagulant pathways leading to intra-alveolar thrombin formation and fibrin deposition [3-7]. Despite the fact that these hallmark features of ALI are well described, the specific timing of

\footnotetext{
* Correspondence: Julie.bastarache@vanderbilt.edu

${ }^{2}$ Division of Allergy, Pulmonary, and Critical Care Medicine, Vanderbilt University School of Medicine, Nashville, USA

Full list of author information is available at the end of the article
}

increased permeability, influx of inflammatory cells and activation of coagulation are unknown. Given the lack of specific therapies for ALI, a detailed understanding of the kinetics of activation of coagulation pathways and the relationship to other indices of lung injury is particularly important so that coagulation-targeted therapies may be administered at the correct time in the course of injury.

Inflammatory cell influx into the airspace has been well studied. In mice, one of the major chemotactic factors contributing to neutrophil recruitment to the lung is CXCL1, an early proinflammatory chemokine that plays a key role in recruitment of inflammatory cells [8], Although animal studies aimed at preventing neutrophil 
recruitment to the lung have been promising [9], there have not been any major breakthroughs in the development of new therapeutics for human ALI [2]. Inflammation and coagulation are tightly linked processes with inflammatory cytokines leading to upregulation of Tissue Factor (TF) on lung epithelial cells [10], macrophages $[11,12]$ and endothelial cells [13]. Studies suggest that generation of thrombin as a result of TF activation leads to inflammatory cell recruitment. Coagulation and inflammation are linked through protease activated receptors (PAR) and thrombin-mediated signaling through PAR-1 on vascular cells increases production of chemokines such as MCP-1, resulting in the efficient recruitment of leukocytes in a mouse-to-rat heart transplant model [14]. These studies suggest that targeting coagulation pathways in ALI may lead to changes in inflammation. Thus a more detailed understanding of the temporal relationship between coagulation and inflammation is needed to identify the underlying molecular mechanisms that regulate inflammation and may lead to the development of novel therapeutic strategies in ALI.

In recent years numerous studies have focused on the role of coagulation pathways in the pathophysiology of ALI/ARDS [6, 7, 10, 15-19]. Among them, TF, the principal initiator of the extrinsic coagulation pathway has been the focus of several studies. Activation of the extrinsic coagulation cascade through up-regulation of TF specifically in the lung epithelium has been implicated in the pathogenesis of acute lung injury $[10,20]$ in humans and animal models [21-25]. We hypothesized that upregulation of lung epithelial TF would occur early in the course of bleomycin injury and would precede inflammatory cell influx. Using the bleomycin-induced acute lung injury model which causes intense lung epithelial injury, a major source of TF in the lung [10], we measured indices of TF upregulation and activation, lung permeability and lung inflammation. The current study focuses on the temporal relationship of multiple aspects of ARDS pathogenesis. While prior animal studies have examined TF expression in response to bleomycin, these studies were focused either on later time points when bleomycin-induced fibrosis is established or on a single aspect of lung injury. In the current study we set out to comprehensively study lung TF regulation, permeability and inflammation in the early inflammatory stages of bleomycin-induced lung injury, something that has not been previously reported. We found that expression of the chemokine CXCL1 occurred by day 1 after IT bleomycin. This was followed by maximal upregulation of TF mRNA and procoagulant activity at day 3 which correlated with increased permeability. Maximal inflammatory cell influx and TF protein expression occurred later at day 6. Taken together, our findings indicate that increased permeability and upregulation of TF in the lung occur early in the course of bleomycin-induced ALI and that these changes precede inflammatory cell recruitment to the lung.

\section{Methods}

Mouse experimental protocol and tissue collection

All the animal experiments were conducted in accordance with the institutional guidelines and were approved by the Vanderbilt Institute for Animal Care and Use Committee. Eight to 10-week-old male and female wild-type (WT) $\mathrm{C} 57 \mathrm{Bl} / 6$ mice were anesthetized with isofluance and given a single direct intra-tracheal (IT) injection of 100uL of 0.04 U bleomycin sulfate (Bristol-Myers Squibb Co., Princeton, NJ) or sterile saline (control) as previously described [21]. Six to 10 mice per group were studied daily on days 1-7. At each time point bleomycin-treated and control mice were sacrificed for BAL and tissue collection. In separate experiments, lung tissue was collected for immunostaining and wet to dry weight ratio. For each measurement, all available specimens were assayed.

\section{Bronchoalveolar lavage cell count and differential}

BAL samples were collected by instilling $900 \mu \mathrm{l} 0.9 \% \mathrm{NaCl}$ and aspirating the fluid. BAL was centrifuged at $1000 \mathrm{xg}$ for $10 \mathrm{~min}$ and supernatant was frozen at $-80{ }^{\circ} \mathrm{C}$. Manual cell counts (hemocytometer) and cytospins/differentials were completed with fresh BAL fluid. Cytospins were stained with Hema 3 staining kit (Thermo-Fisher Scientific, Pittsburg, PA, USA) [21].

\section{Isolation and analysis of TF mRNAs}

RNA was extracted following the commercial protocol with an Invitrogen Pure Link RNA mini kit and quantified by absorbance at $260 \mathrm{~nm}$. mRNA $(1 \mu \mathrm{g})$ was used to synthesize first-strand cDNA with a SuperScript VILO cDNA kit (Invitrogen). Quantitative real-time PCR was performed using Assays-on-Demand primer/MGB probes (TaqMan probe/primer sets, Applied Biosystems) for murine TF (Mm00438853) and GAPDH (Mm99999915). All values were normalized to the GAPDH mRNA content of each sample.

\section{Murine TF quantification by ELISA}

To quantify TF protein in whole lung homogenate, we developed a novel murine TF ELISA. General ELISA processing and procedures for assay development was performed as previously described [26]. All lung homogenate test samples were assayed in duplicate. Standard curves for quantitation of TF levels within the homogenates were generated by spiking known quantities of purified recombinant mouse TF (R\&D systems) into each well which was captured utilizing a rat monoclonal anti-TF antibody (generously provided by Daniel Kirchofer, Genentech, San Francisco, CA) and detected utilizing a 
goat polyclonal anti-TF antibody (R\&D systems). As initial experiments demonstrated that quantitation of known TF levels in standard assay buffer supplemented with $1 \%$ BSA performed equivalently to parallel experiments in lung tissue homogenate, $1 \% \mathrm{BSA}$ was utilized as the sample matrix for all standards.

\section{BAL TATC and CXCL1 concentration by ELISA}

TATc (Enzygnost ${ }^{\circ}$ TAT micro kit, Siemens, Tarrytown, NY) and CXCL1 (DuoSet, R\&D Systems, Minneapolis, MN) were quantified by ELISA according to manufacturers instructions.

\section{Clot time measurement}

Clot time was measured using a mechanical clot detection system (STart4 Coagulometer; Diagnostica Stago, Paris, France) according to published methods [21]. Briefly, $25 \mu \mathrm{l}$ of BAL was warmed for $15 \mathrm{~min}$ at $37{ }^{\circ} \mathrm{C}$ then incubated with $25 \mu \mathrm{l}$ of pooled citrated mouse plasma (Bioreclamation, East Meadow, New York). Clot time was determined in duplicate as plasma recalcification time following the addition of $25 \mu \mathrm{l}$ of $50 \mathrm{mM}$ calcium chloride.

\section{BAL protein measurements}

Protein was measured in BAL using the BCA protein assay (Pierce, Rockford, Illinois, USA).

\section{Lung TF immunostaining}

Formalin-fixed and paraffin-embedded lung sections from day 1 , day 3 , day 5 and day 7 were immunostained for TF. Lung sections were de-paraffinised with antigen retrieval by standard procedures as previously described [21]. Slides were incubated overnight at $4{ }^{\circ} \mathrm{C}$ with 1: 200 goat polyclonal anti-TF Ab (R\&D Systems), rinsed and incubated with a biotinylated rabbit anti-goat secondary antibody (Innogenex, San Ramon, California) for 20 min at room temperature. Slides were developed with NovoRed
(Vector, Burlingame, California) for 30s and counterstained with methyl green for 10 s.

\section{Lung wet-to-dry weight ratio}

The left lung was placed on pre-weighed aluminum foil, weighed and placed in an $80^{\circ} \mathrm{C}$ oven for 2 days. The foil + lung was weighed again and the ratio was calculated ((lung - foil before drying)/(lung - foil after drying)).

\section{Statistical analysis}

Normally distributed data are displayed as bar graphs showing mean and SEM. Comparison of three or more groups was done using one-way analysis of variance with post hoc Tukey test. Comparison of the two groups was by Student's $t$ test. All analyses were done with SPSS software version 22 for Macintosh. $p<0.05$ was considered statistically significant.

\section{Results}

TF regulation in the time course of bleomycin-induced ALI

In order to define the time course of TF regulation we measured TF mRNA and protein (Fig. 1), cellular localization by immunostaining (Fig. 2) and activity (Fig. 3) over time in response to IT bleomycin treatment. In the bleomycin treated group, TF mRNA increased slightly starting at day 2 with peaks at day 4 (Fig. 1a). TF protein in whole lung homogenates as measured by ELISA (normalized to total protein) increased daily and peaked at day 6 (Fig. 1b). Increased TF protein expression in the lung epithelium was evident by day 1 by TF immunostaining (Fig. 2). Staining became more patchy and intense on days 3 and 5 and persisted on day 7 . These increases in TF mRNA and protein were paralleled by increased TF procoagulant activity in BAL fluid (Fig. 3a) which also peaked at day 4. Consistent with TF procoagulant activity and generation of thrombin,
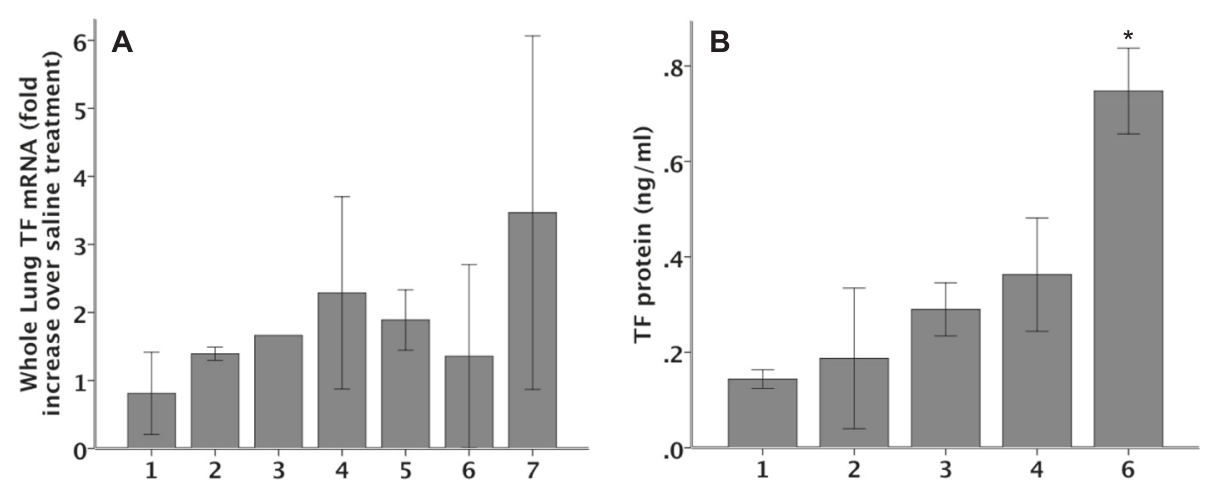

Fig. 1 TF mRNA and protein expression in whole lung over time. TF mRNA (a) and protein (b) were measured in whole lung from bleomycin treated mice. There was a non-significant increase in TF mRNA starting at day 2 with the peak at day 4 . The right panel shows TF protein concentration in lung homogenate as measured by TF ELISA. $N=2-5$ per group. ${ }^{*} p<0.007$ versus all other groups by ANOVA with post-hoc Tukey test 

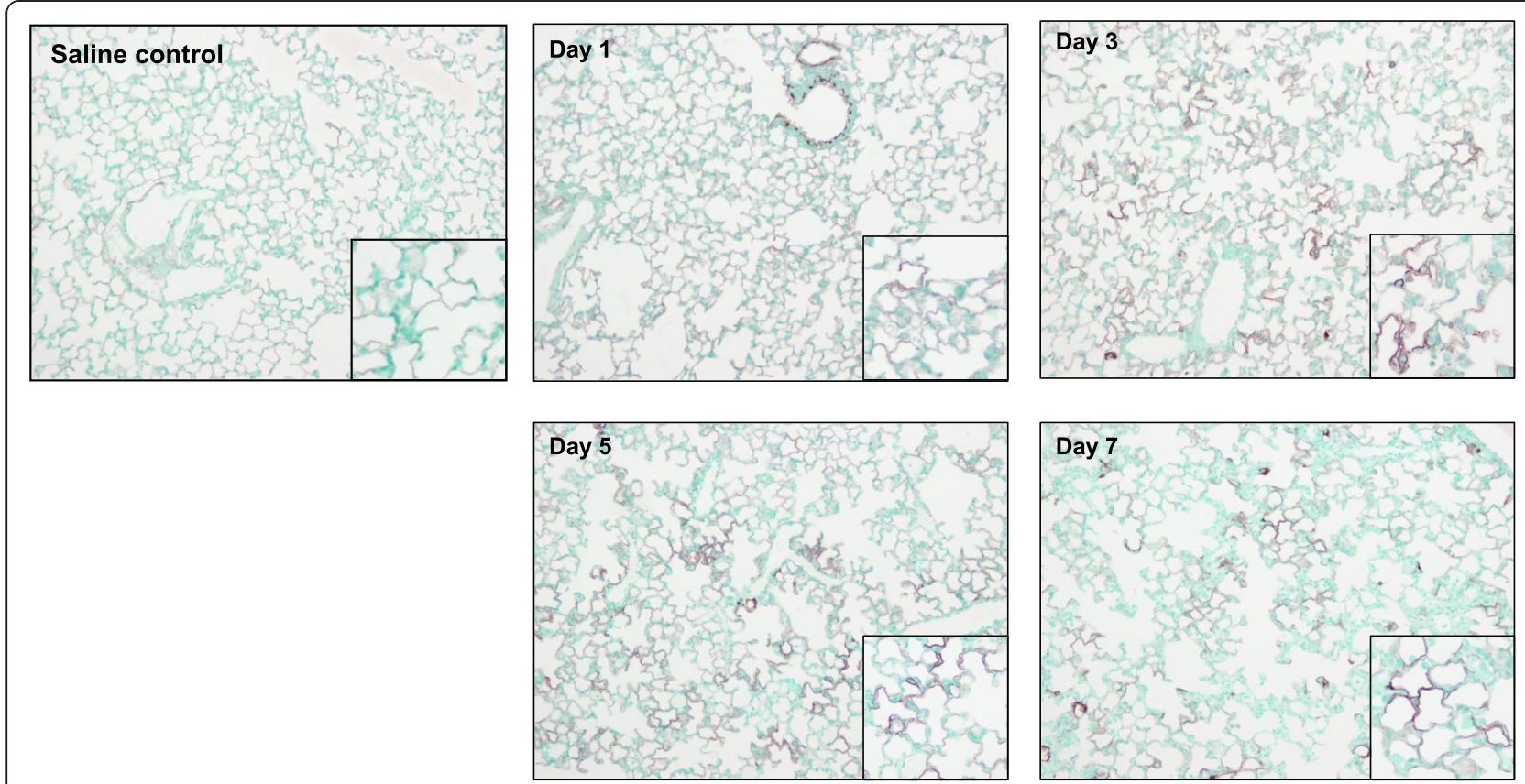

Fig. 2 TF protein localization in lungs following IT Bleomycin. TF protein expression in mouse lung measured by TF immunostaining by days after bleomycin treatment. A saline control treated animal is shown in the left panel for comparison. Larger images at 10x power, insets at 20x power

thrombin anti-thrombin complexes started to increase at day 3 and peak on day 6 (Fig. 3b).

\section{C57BL/6 mice have increased pulmonary edema in response to intra-tracheal bleomycin}

Bleomycin treated mice had increased BAL protein concentration, an indicator of lung vascular permeability. Compared to day 1 , BAL protein levels were 2- to 4-fold higher on days 3-7 (Fig. 4a) suggesting that increased permeability in response to IT bleomycin persists for the first week after injury. Similarly, mice had significant increases in wet-to-dry weight ratio by day 3 following treatment with IT bleomycin (Fig. 4b). This increase in excess lung water persisted out to 7 days.

\section{Inflammatory response to IT bleomycin}

In order to investigate the early inflammatory response following IT bleomycin, mice were studied daily for 7 days with BAL cell counts with differentials and CXCL1 levels. BAL CXCL1 levels peaked at day 1 and rapidly declined (Fig. 5a). BAL cell counts started to increase by day 3 but peaked on day 6 (Fig. 5b). The majority of inflammatory cells were macrophages at all time points (Fig. 5c) but there were also significant increases in neutrophils (day 6) and lymphocytes (days 4-7).
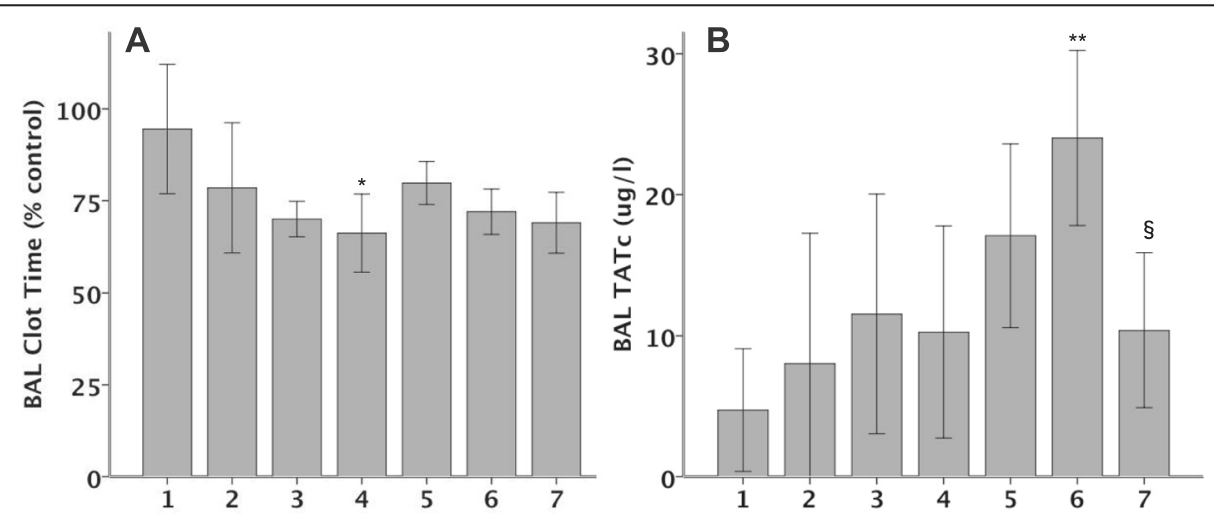

Fig. 3 BAL procoagulant activity over time. TF procoagulant activity was measured by BAL clot time (Panel a) and BAL thrombin-antithrombin complexes (Panel b) over time in response to IT bleomycin. Clot time is expressed as percent of the saline-treated animals on the same day. $N=5-6$ per group. ${ }^{*} p=0.024$ versus day $1{ }^{* *} p<0.001$ and $\S p=0.028$ versus PBS control by $t$ test on each day 

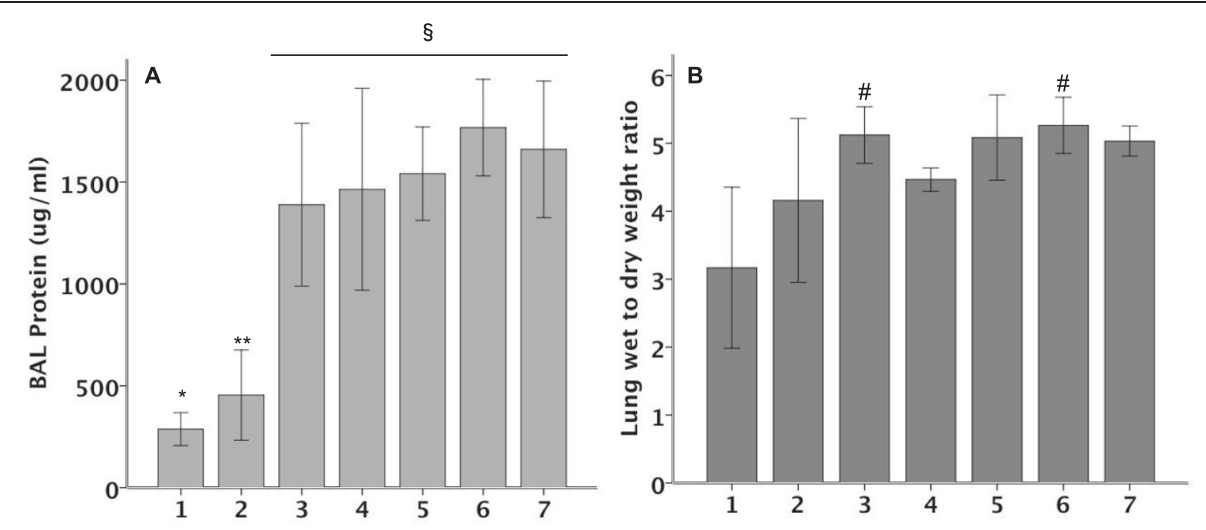

Fig. 4 BAL protein (Panel a) and wet to dry lung weight ratio (Panel b) over time on mice treated with IT Bleomycin. $N=5-6$ per group. ${ }^{*} p=0.006$, ${ }^{* *} p=0.017, \$ p<0.001, \# p<0.05$ versus PBS treatment by $t$ test

\section{Discussion}

Acute lung injury and its most severe form, acute respiratory distress syndrome (ARDS) are marked by severe hypoxemia, diffuse alveolar damage, profound influx of activated inflammatory cells into alveoli, along with protein-rich pulmonary edema accumulation that impairs lung function [27]. As mechanisms of ALI pathophysiology have been elucidated with time, other important pathways that mediate the lung injury response have been identified including activation of coagulation, specifically by upregulation of TF on the lung epithelium [10, 15]. Among these factors involved in ALI pathophysiology, neutrophil migration is a hallmark of ALI and is induced through a complex interplay of adhesion molecules, cytokines and chemokines [28]. Another hallmark of ALI is increased alveolar-capillary permeability leading to influx of protein rich edema fluid into the airspace. The mechanisms that regulate permeability have been studied and include thrombin activation and fibrin deposition that enhance lung inflammation, activate endothelial cells and disrupt lung paracellular permeability
[29]. Others have shown that TF is upregulated in the lung in response to bleomycin-induced lung injury $[22-25,30]$ and that procoagulant pathways are important in modulating the development of pulmonary fibrosis following an acute insult. Our prior work has focused on regulation of coagulation proteins by the lung epithelium. In ALI, the lung epithelium upregulates TF mRNA, protein and procoagulant activity [10] and releases TF positive procoagulant microparticles [15] leading to a shift towards procoagulant pathways in the airspace that are not balanced by anticoagulant pathways such as tissue factor pathway inhibitor (TFPI) [16]. While other important studies have established a critical role for TF in modulating lung coagulation, inflammation, permeability and fibrosis in the later stages of bleomycin induced lung injury (7-28 days), relatively little is known about the relationship between TF and ALI in very early bleomycin induced lung injury.

In this study we define the time course of TF expression, lung permeability and inflammation in a direct model of bleomycin-induced acute lung injury. Because

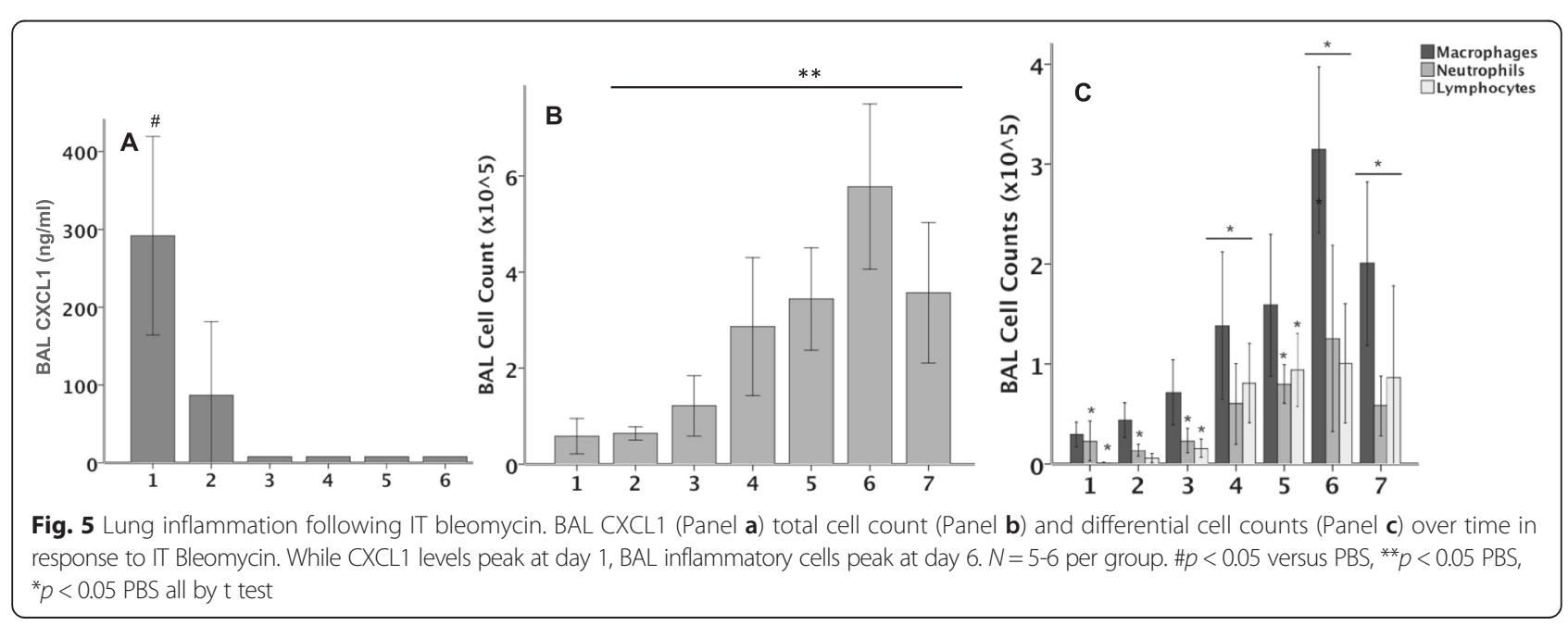


the lung epithelium is a major source of TF in the airspace, we chose a model of ALI, intratracheal bleomycin, that causes significant lung epithelial injury. While our prior studies do establish that the lung epithelium is a major source of TF, the relationship between TF and lung permeability and inflammation in the early stages of ALI are unknown.

In this study we define the kinetics of TF expression in the lung at the mRNA, protein and activity level. We were surprised to find that the peak in total lung TF expression at day 6 occurred after the peak in procoagulant activity as measured by clot time. There are several possible explanations for this finding. First, it may be that the early upregulation of TF in the lung results in the release of large numbers of TF containing procoagulant microparticles (MPs). We have previously shown that there are high concentrations of TF containing MPs in the airspace in ARDS [15]. Our measurements of TF by ELISA were done on lungs that had been lavaged (BAL) prior to snap freezing. It is possible that this lavage removed TF containing MPs that had been released by the lung epithelium and thus our ELISA data do not represent the total amount of TF generated by the lung. BAL will also remove alveolar macrophages, another potential source of TF in the lung [31]. Another potential explanation for the differences in timing of TF mRNA, protein and procoagulant activity is that although TF transcription is not increasing from days $4-7$, TF translation may be increased resulting in more TF protein. We did not study TF translation in these experiments so this remains an unanswered question. Other groups have shown increases in TF mRNA in response to bleomycin while our increases were modest and not statistically significant. Olman et al. showed a 2.3 -fold increase by day 1 and a 3.8-fold increase by day 4 in TF mRNA [24]. One potential explanation for this discrepancy is that our study was underpowered to find a statistically significant difference in mRNA. There may also be differences related to measurement technique and bleomycin dose (higher in the Olman study). Alternatively, TF mRNA may be increased in a selected cell population, such as the lung epithelium, which may be obscured by measuring TF mRNA in the whole lung. Finally, we found elevated TATc levels suggest that active TF results in downstream activation of the coagulation cascade. It is well known that the concentration of TATc in blood reflects the formation of thrombin [32, 33] and serves as a sensitive marker for the activation of coagulation $[34,35]$. In the bleomycin group the increase in TAT level provided evidence of a downstream activation of the coagulation pathway in the airspace in the early stage of ALI.

In the current study, we show that increased BAL CXCL1 is the earliest change in the lung (day 1) followed by increase permeability (days $3-7$ ) and increased TF mRNA and procoagulant activity by day 4 . All of these changes precede the influx of inflammatory cells which peak at day 6. CXCL1 is known to be important in neutrophil recruitment in bleomycin-induced acute lung injury. Russo et al. showed an early increase in lung tissue CXCL1 6 hours after bleomycin that persisted through day 4 [36]. Interestingly, this group also showed that BAL neutrophil influx was delayed, peaking at day 8. This was similar to our findings of CXCL1 increase on day 1 followed by neutrophil influx on day 6 . Whether other chemokines drive neutrophil influx into the airspace in the bleomycin model remains to be seen. We were surprised to find that changes in TF and permeability persistent through day 7 despite reduced inflammation by this time point. One explanation for this finding is that mechanisms other than inflammation and coagulation affect disruption of the alveolar-capillary barrier. However, an alternative possibility is that a secondary lung insult, such as infection, may have developed within the first week. Further work is needed to elucidate mechanisms affecting prolonged permeability disruption after bleomycin.

One surprising finding is that the permeability changes occurred early and preceded increases in TF or TATc formation. This suggests the possibility that influx of mediators from the plasma into the airspace are necessary either for upregulation of lung TF or for activation of downstream coagulation. Although it is well described by our group and others that TF protein and activity is regulated locally in the lung epithelium $[10,20]$, whether resident lung cells can make other necessary coagulation factors such as factors VII, X, prothrombin and fibrinogen is unknown. It is possible that although the lung epithelium can upregulate TF, proteins from the circulation are needed for propagation of coagulation and generation of thrombin and fibrin. Our study as designed cannot definitively answer this question but the temporal relationship between increased permeability and activation of coagulation suggests this as one possibility. This study adds to the growing body of literature supporting an integral role for TF in mediating lung injury, permeability and inflammation.

There are some limitations to this study. First of all, we only studied one chemokine, CXCL1, in the time course but there are other chemokines and cytokines that may play important roles. Prior studies of bleomycin-induced ALI have demonstrated that interleukin (IL)-1 $\beta$, IL-6, IL-8, and MIP-2a/CXCL2a, which are associated with inflammation are increased in bleomycin induced lung injury [37, 38]. Second, we found that BAL inflammatory cells were maximal at day 6 which occurred after maximal coagulation activation. This suggests TF may be important in the recruitment of inflammatory cells to lung but how TF 
upregulation in the lung may influence inflammatory cell recruitment to the airspace is unknown and requires further study. Finally, our study is descriptive in nature although it provides critical information of the timing of TF regulation and activation in relationship to permeability and inflammation in the lung.

\section{Conclusions}

In this study of kinetics of TF, permeability and inflammation in early bleomycin induced lung injury, we found that permeability changes precede upregulation in TF supporting the concept that therapies aimed at limiting alveolar capillary permeability may have the potential to influence regulation and activation of TF. Likewise, the fact that TF activity peaks prior to the peak in inflammatory cell influx suggest that strategies aimed at modulating TF activity have the potential to influence inflammation in the lung. Future studies will build on these important findings to test the therapeutic potential of modulating TF in the lung in ALI.

\section{Competing interests}

The authors declare that they have no competing interests.

\begin{abstract}
Authors' contributions
LM carried out the PCR and coagulation assays and wrote the initial draft of the manuscript; CMS did the cytokine measurements, helped with statistical analysis, and edited the manuscript; BSG prepared CDNA and RNA and did TF immunostaining; DBM and NEW did all of the mouse injections and tissue harvests as well as cell counts and differentials; RHC, TLC, BEB developed the mouse TF ELISA; LBW and JAB designed the study, supervised experimental procedures, analyzed data and wrote and edited the manuscript. All of the authors read and approved the final manuscript.
\end{abstract}

\section{Acknowledgements}

NIH HL087738, HL103836, HL090785, HL117676 and an AHA Clinical Research Program Award and Established Investigator Award Program.

\section{Author details}

'Division of Emergency Intensive Care Unit, the Second Hospital of Lanzhou University, Lanzhou, China. ${ }^{2}$ Division of Allergy, Pulmonary, and Critical Care Medicine, Vanderbilt University School of Medicine, Nashville, USA. ${ }^{3}$ Department of Cancer Biology, Vanderbilt University School of Medicine, Nashville, USA. ${ }^{4}$ Vanderbilt Institute for Chemical Biology, Nashville, USA. ${ }^{5}$ Department of Pathology, Microbiology and Immunology, Vanderbilt University School of Medicine, Nashville, USA.

Received: 11 February 2015 Accepted: 31 May 2015

Published online: 21 June 2015

\section{References}

1. Mizgerd JP. Acute lower respiratory tract infection. N Engl J Med. 2008:358(7):716-27. Epub 2008/02/15.PMCID:18272895.

2. Seeley EJ, Matthay MA, Wolters PJ. Inflection points in sepsis biology: from local defense to systemic organ injury. Am J Physiol Lung Cell Mol Physiol. 2012;303(5):L355-63. Epub 2012/06/19.PMCID:22707617.

3. Ware LB, Matthay MA. The acute respiratory distress syndrome. N Engl J Med. 2000;342(18):1334-49. PMCID:10793167.

4. Idell S. Coagulation, fibrinolysis, and fibrin deposition in acute lung injury. Crit Care Med. 2003:31(4 Suppl):S213-20. PMCID:12682443.

5. Idell $\mathrm{S}$, Cohen AB. Bronchoalveolar lavage in patients with the adult respiratory distress syndrome. Clin Chest Med. 1985;6(3):459-71. PMCID:3907947.

6. Idell S, Gonzalez K, Bradford H, MacArthur CK, Fein AM, Maunder RJ, et al. Procoagulant activity in bronchoalveolar lavage in the adult respiratory distress syndrome. Contribution of tissue factor associated with factor VII. Am Rev Respir Dis. 1987;136(6):1466-74. PMCID:3688650.

7. Idell S, Koenig KB, Fair DS, Martin TR, McLarty J, Maunder RJ. Serial abnormalities of fibrin turnover in evolving adult respiratory distress syndrome. Am J Physiol. 1991;261(4 Pt 1):L240-8. PMCID:1928357.

8. Rossi DL, Hurst SD, Xu Y, Wang W, Menon S, Coffman RL, et al. Lungkine, a novel CXC chemokine, specifically expressed by lung bronchoepithelial cells. J Immunol. 1999;162(9):5490-7. Epub 1999/05/05.PMCID:10228029.

9. Aulakh GK, Suri SS, Singh B. Angiostatin inhibits acute lung injury in a mouse model. Am J Physiol Lung Cell Mol Physiol. 2014;306(1):L58-68. Epub 2013/11/12.PMCID:24213918.

10. Bastarache JA, Wang L, Geiser T, Wang Z, Albertine KH, Matthay MA, et al. The alveolar epithelium can initiate the extrinsic coagulation cascade through expression of tissue factor. Thorax. 2007;62(7):608-16. PMCID:17356058.

11. Haugen TS, Nakstad B, Lyberg T. Heterogeneity of procoagulant activity and cytokine release in subpopulations of alveolar macrophages and monocytes. Inflammation. 1999;23(1):15-23. PMCID:10065758.

12. Gilmour PS, Morrison ER, Vickers MA, Ford I, Ludlam CA, Greaves M, et al. The procoagulant potential of environmental particles (PM10). Occup Environ Med. 2005;62(3):164-71. Epub 2005/02/23.PMCID:15723881.

13. Wygrecka M, Markart P, Ruppert C, Kuchenbuch T, Fink L, Bohle RM, et al. Compartment- and cell-specific expression of coagulation and fibrinolysis factors in the murine lung undergoing inhalational versus intravenous endotoxin application. Thromb Haemost. 2004;92(3):529-40. PMCID:15351849.

14. Chen D, Carpenter A, Abrahams J, Chambers RC, Lechler Rl, McVey JH, et al. Protease-activated receptor 1 activation is necessary for monocyte chemoattractant protein 1-dependent leukocyte recruitment in vivo. J Exp Med. 2008;205(8):1739-46. Epub 2008/07/09.PMCID:18606855.

15. Bastarache JA, Fremont RD, Kropski JA, Bossert FR, Ware LB. Procoagulant alveolar microparticles in the lungs of patients with acute respiratory distress syndrome. Am J Physiol Lung Cell Mol Physiol. 2009;297(6):L1035-41. Epub 2009/ 08/25.PMCID:19700643.

16. Bastarache JA, Wang L, Wang Z, Albertine KH, Matthay MA, Ware LB. Intra-alveolar tissue factor pathway inhibitor is not sufficient to block tissue factor procoagulant activity. Am J Physiol Lung Cell Mol Physiol. 2008;294(5):L874-81. PMCID:18310227.

17. Fuchs-Buder T, de Moerloose P, Ricou B, Reber G, Vifian C, Nicod L, et al. Time course of procoagulant activity and $D$ dimer in bronchoalveolar fluid of patients at risk for or with acute respiratory distress syndrome. Am J Respir Crit Care Med. 1996;153(1):163-7. PMCID:8542111.

18. Gando S, Kameue T, Matsuda N, Hayakawa M, Morimoto Y, Ishitani T, et al. Imbalances between the levels of tissue factor and tissue factor pathway inhibitor in ARDS patients. Thromb Res. 2003;109(2-3)):119-24. PMCID:12706640.

19. Idell S, James KK, Levin EG, Schwartz BS, Manchanda N, Maunder RJ, et al. Local abnormalities in coagulation and fibrinolytic pathways predispose to alveolar fibrin deposition in the adult respiratory distress syndrome. J Clin Invest. 1989;84(2):695-705. PMCID:2788176.

20. Bastarache JA, Sebag SC, Grove BS, Ware LB. Interferon-gamma and tumor necrosis factor-alpha act synergistically to up-regulate tissue factor in alveolar epithelial cells. Exp Lung Res. 2011;37(8):509-17. Epub 2011/09/ 15.PMCID:21913843.

21. Bastarache JA, Sebag SC, Clune JK, Grove BS, Lawson WE, Janz DR, et al. Low levels of tissue factor lead to alveolar haemorrhage, potentiating murine acute lung injury and oxidative stress. Thorax. 2012;67(12):8. Epub 2012/10/04.PMCID:23033361.

22. Idell S, Gonzalez KK, MacArthur CK, Gillies C, Walsh PN, McLarty J, et al. Bronchoalveolar lavage procoagulant activity in bleomycin-induced lung injury in marmosets. Characterization and relationship to fibrin deposition and fibrosis. Am Rev Respir Dis. 1987;136(1):124-33. PMCID:2440356.

23. Idell S, James KK, Gillies C, Fair DS, Thrall RS. Abnormalities of pathways of fibrin turnover in lung lavage of rats with oleic acid and bleomycin-induced lung injury support alveolar fibrin deposition. Am J Pathol. 1989;135(2):387-99. PMCID:2476934.

24. Olman MA, Mackman N, Gladson CL, Moser KM, Loskutoff DJ. Changes in procoagulant and fibrinolytic gene expression during bleomycin-induced lung injury in the mouse. J Clin Invest. 1995;96(3):1621-30. PMCID:7544811.

25. Wygrecka M, Markart P, Ruppert C, Petri K, Preissner KT, Seeger W, et al. Cellular origin of pro-coagulant and (anti)-fibrinolytic factors in bleomycin- 
injured lungs. Eur Respir J. 2007;29(6):1105-14. Epub 2007/03/ 03.PMCID:17331968.

26. Markham NO, Cooper T, Goff M, Gribben EM, Carnahan RH, Reynolds AB. Monoclonal antibodies to DIPA: a novel binding partner of p120-catenin isoform 1. Hybridoma (Larchmt). 2012;31(4):246-54. Epub 2012/08/ 17.PMCID:22894777.

27. Bhadade RR, de Souza RA, Harde MJ, Khot A. Clinical characteristics and outcomes of patients with acute lung injury and ARDS. J Postgrad Med. 2011;57(4):286-90. Epub 2011/11/29.PMCID:22120856.

28. Ley K, Laudanna C, Cybulsky MI, Nourshargh S. Getting to the site of inflammation: the leukocyte adhesion cascade updated. Nat Rev Immunol. 2007;7(9):678-89. Epub 2007/08/25.PMCID:17717539.

29. Gonzales JN, Kim KM, Zemskova MA, Rafikov R, Heeke B, Varn MN, et al. Low anticoagulant heparin blocks thrombin-induced endothelial permeability in a PAR-dependent manner. Vascul Pharmacol. 2014;62(2):63-71. Epub 2014/ 01/29.PMCID:24469066

30. Scotton CJ, Krupiczojc MA, Konigshoff M, Mercer PF, Lee YC, Kaminski N, et al. Increased local expression of coagulation factor $X$ contributes to the fibrotic response in human and murine lung injury. J Clin Invest. 2009. Epub 2009/08/05.PMCID:19652365

31. Drake TA, Morrissey JH, Edgington TS. Selective cellular expression of tissue factor in human tissues. Implications for disorders of hemostasis and thrombosis. Am J Pathol. 1989;134(5):1087-97. PMCID:2719077.

32. Nossel HL, Butler Jr VP, Wilner GD, Canfield RE, Harfenist EJ. Specificity of antisera to human fibrinopeptide A used in clinical fibrinopeptide A assays. Thromb Haemost. 1976;35(1):101-9. Epub 1976/02/29.PMCID:60791.

33. Pelzer $H$, Schwarz A, Heimburger N. Determination of human thrombinantithrombin III complex in plasma with an enzyme-linked immunosorbent assay. Thromb Haemost. 1988:59(1):101-6. Epub 1988/02/25.PMCID:3363526.

34. Franchini M. Haemostasis and pregnancy. Thromb Haemost. 2006;95(3):401-13. Epub 2006/03/10.PMCID:16525566.

35. Eichinger S, Weltermann A, Philipp K, Hafner E, Kaider A, Kittl EM, et al. Prospective evaluation of hemostatic system activation and thrombin potential in healthy pregnant women with and without factor $\mathrm{V}$ Leiden. Thromb Haemost. 1999;82(4):1232-6. Epub 1999/11/02.PMCID:10544904.

36. Russo RC, Guabiraba R, Garcia CC, Barcelos LS, Roffe E, Souza AL, et al. Role of the chemokine receptor CXCR2 in bleomycin-induced pulmonary inflammation and fibrosis. Am J Respir Cell Mol Biol. 2009;40(4):410-21. Epub 2008/10/ 07.PMCID:18836137.

37. Chu AJ. Tissue factor mediates inflammation. Arch Biochem Biophys 2005;440(2):123-32. Epub 2005/07/23.PMCID:16036212.

38. Chu AJ. Tissue factor upregulation drives a thrombosis-inflammation circuit in relation to cardiovascular complications. Cell Biochem Funct. 2006:24(2):173-92. Epub 2004/12/24.PMCID:15617024.

\section{Submit your manuscript to a SpringerOpen ${ }^{\circ}$ journal and benefit from:}

- Convenient online submission

- Rigorous peer review

- Immediate publication on acceptance

- Open access: articles freely available online

- High visibility within the field

- Retaining the copyright to your article

Submit your next manuscript at $\gg$ springeropen.com 